\title{
Analysis of the Global Swell and Wind Sea Energy Distribution Using WAVEWATCH III
}

\author{
Kaiwen Zheng, ${ }^{1}$ Jian Sun, ${ }^{1}$ Changlong Guan, ${ }^{1}$ and Weizeng Shao ${ }^{2}$ \\ ${ }^{1}$ Physical Oceanography Laboratory, Ocean University of China, 238 Songling Road, Qingdao 266100, China \\ ${ }^{2}$ Zhejiang Ocean University, Zhoushan 316000, China \\ Correspondence should be addressed to Jian Sun; sunjian77@ouc.edu.cn
}

Received 21 August 2015; Revised 3 November 2015; Accepted 26 November 2015

Academic Editor: Xiaofeng Li

Copyright (c) 2016 Kaiwen Zheng et al. This is an open access article distributed under the Creative Commons Attribution License, which permits unrestricted use, distribution, and reproduction in any medium, provided the original work is properly cited.

\begin{abstract}
Over the past several decades, an increasing number of studies have focused on the global view of swell and wind sea climate. However, our understanding of wind sea and swell is still incomplete as is the lack of an integrated description for all the wave components. In this paper, the European Centre for Medium-Range Weather Forecasts (ECMWF) Era-medium wind data is used to run the WAVEWATCH III model and the global wave fields in 2010 are reproduced. Using the spectra energy partition (SEP) method, two-dimensional wave spectra were separated and detailed information for the components of wind sea and swell was obtained. We found that the highest seasonal mean energy of swell and wind sea are distributed in the respective winter hemispheres. In most seas, swell carries a large part of the wave energy with $W_{s}$ being higher than $50 \%$. Compared to swell, the global distribution of wind sea energy is highly affected by the seasons. We also established a link between inverse wave age and the ratio of swell energy to total wave energy. This study aims to improve our understanding of surface wave energy composition and thus the parameterization of global-scale wind-wave interaction and air-sea momentum flux.
\end{abstract}

\section{Introduction}

Ocean surface gravity waves are the medium that transfers energy across the air-sea surface. The energy value is enormous. It was estimated by Wang and Huang [1] that the global wind energy input for the formation of surface waves is $60 \mathrm{TW}$. This enormous energy has different destinations. Some portion is transported into the subsurface ocean, playing a major role in regulating the general circulation of the ocean [2]. Some portion dissipates with tides, coastal surges, and others. Some portion is even transported back to the atmosphere through air-sea interaction. From results obtained during several sea expeditions, Grachev and Fairall (2001) [3] found that, in the equatorial west Pacific Ocean, upward energy and momentum transfer occurs about $10 \%$ of the time.

Surface gravity waves are classified into two categories, wind sea waves and swells. Wind seas and swells have completely different characteristic features. Wind seas are locally generated, are of short wavelength, are more chaotic, and travel more slowly than surface wind. They require energy from wind to grow [4]. In contrast, swells are usually generated remotely by storms, are of long wavelength, have a smoother appearance, and can propagate thousands of kilometers across the ocean, without extracting energy from wind. In every area of the ocean, the sea state is mixed, with the components of both wind seas and swells composed together. The lack of knowledge of mixed wave energy composition limits the understanding of air-sea energy exchange. Since sea surface roughness is due mainly to surface gravity waves, the presence of swells and wind seas is a key factor in parameterizing the drag coefficient $[5,6]$. Moreover, for the study of global-scale wind-wave interaction and air-sea momentum flux, isolating wind seas and swells from mixed waves is also meaningful.

In recent years, researchers have used various techniques and methods to study the spatial and seasonal distribution of swell and wind sea energy. Barstow (1996) [7] and Young (1999) [8] used satellite altimetry and wave models to study the distribution. This study focuses on the wave parameters 
of significant wave height (SWH) and mean wave period (MWP). However, these two parameters cannot adequately describe the components of ocean waves, as even two fields with completely the same SWH and MVP may vary considerably in detail [9]. Gulev and Hasse (1998) [10] presented a global distribution of SWH, wind sea, and swell heights covering a period of more than 40 years from voluntary observing ships (VOS). Liu et al. (2002) [11] analyzed the temporal and spatial variation of northern Pacific Ocean wave fields covering a period from 1950 to 1995, using visual wave observations from meteorological observation ships. These studies used observers' subjective standard to classify wind seas and swells, and so the accuracy of the separation result is limited. On the basis of satellite data including wind speed and SWH, Chen et al. (2002) [12] used the wind-wave relation for fully developed seas given by Pierson and Moskowitz (1964) [13] to identify swells or wind seas and published a spatial and seasonal pattern of dominant swell and wind sea zones. As mentioned by Chen et al. (2002) [12], this standard can only be expected to be meaningful from a statistical point of view. Model reanalysis data can provide global wave information, with an improvement of the model's simulation ability, and more and more studies are using reanalysis data to study the global wave energy distribution. Zhang et al. (2011) [14] used wind speed, SWH, MWP, and mean wave direction (MWD) from the ECMWF Re-Analysis (ERA-40) data to analyze the global distribution of swell. Semedo et al. (2011) [9], using the $45 \mathrm{yr}$ ECMWF Re-Analysis (ERA-40) data, studied the detailed global climatology of wind sea and swell properties. Although the ECMWF Re-Analysis (ERA-40) data is reliable, downloading detailed spectral information is limited.

Spectral partitioning is an effective way to isolate wind seas and swells from mixed waves $[15,16]$. The SEP (spectra energy partition) method given by Hanson and Jensen (2004) [17] has proved to be valid and was transplanted into the WAVEWATCH III model in 2006 [18]. In this study, we used the year of 2010 ECMWF Era-Interim wind data to run the WAVEWATCH III model and to reproduce the global wave fields. Based on the directional spectrum, all the detailed parameters of wind seas and swells were extracted from the mixed waves. Using the result, we analyzed the spatial and seasonal distribution of wind sea and swell energy. NDBC (National Data Buoy Center) buoy data is also used in this study to examine the model output and calculate inverse wave age.

Section 2 describes the SEP method and some settings of running the WAVEWATCH III model. In this section, the examination results between model output and NDBC records are also displayed. We separated buoy directional spectra and obtained spectral parameters. We tried to establish the relationship between inverse wave age and $W_{s}$ (swell energy proportion to total wave energy) and the result is discussed in Section 3. The 2010 spatial and seasonal distribution of wind sea and swell energy of global wave fields is also presented in Section 3. In Section 3, two indicators, $W_{s}$ (the swell energy proportion to the total wave energy) and $P_{s}$ (swell probability), are calculated. Using $W_{s}$, we found some distinctive areas with high values of wind sea or swell energy. The conclusions and suggestions for further study are presented in Section 4.

\section{Data and Methodology}

2.1. The Spectra Energy Partition (SEP) Method. The SEP method originates from the digital image processing watershed algorithm [19] and was first used by Hanson and Jensen (2004) to separate a two-dimensional wave spectrum. Basically with this method, if the two-dimensional surface wave spectrum is inverted, spectral peaks become catchments and watershed lines or partition boundaries can be determined using the watershed algorithm. Then wind seas and swells are identified using a wave age criterion between the various components of its wind speed and direction. This method has proved to be highly accurate and was transformed to an efficient FORTRAN routine by Hanson et al. (2006) [18] for use in the WAVEWATCH III model.

2.2. Model Settings. The latest WAVEWATCH III official version 4.18 is used in this paper. The wind field is the $10 \mathrm{~m}$ wind speed from the ECWMF ERA-Interim datasets which are regularly gridded and cover from $75^{\circ} \mathrm{N}$ to $75^{\circ} \mathrm{S}$ and $180^{\circ} \mathrm{W}$ to $180^{\circ} \mathrm{E}$, with $0.25^{\circ}$ resolution. The time period was from 1 December 2009 to 31 December 2010 with a 6-hour interval. The water depth field was processed by the Gridgen 3.0 packet according to the NGDC (National Geophysical Data Center) ETOPO 1 data; resolution is $0.5^{\circ} \times 0.5^{\circ}$. The domain ranges from $75^{\circ} \mathrm{N}$ to $75^{\circ} \mathrm{S}$ and from $180^{\circ} \mathrm{W}$ to $180^{\circ} \mathrm{E}$. Source terms for energy spectra in the model are set to default. The model integrates the spectrum to a cut-off frequency $f_{h f}$, and above this frequency a parametric tail is applied. The boundary condition is cyclical. The other option settings are 36 directions, and 24 discrete wavenumbers $(0.0412 \sim 0.4060 \mathrm{~Hz}$, 2.4 24.7 s). The model output is two-dimensional (2D) wave energy spectra obtained at each grid point with a time period from 1 January, 2010, to 31 December, 2010, with a 6-hour interval $(365 * 4)$. It is important to point out that the ERAInterim datasets are derived from reanalysis which is different from this paper's output. Reanalysis is a process by which model information and observations of many different sorts are combined in an optimal way to produce a consistent, global best estimate of the various atmospheric, wave, and oceanographic parameters. ERA-Interim uses altimeter wave height observations to constrain the wave spectra predicted by the WAM wave model. All of the ocean wave parameters including significant wave height were extracted from each dimensional spectrum. Also, there are some physical and numerical differences between the WAM and WW3 models.

2.3. Examination Results. Temporal correlation statistical analyses between model output and observed records are a commonly used comparison method to evaluate a model's simulation ability. With this method, Hanson et al. (2006) [18] used a series of nondirectional and directional wave spectra buoy data to quantify the ability of numerical wave models to reproduce measured wave components of height, period, and direction. In this paper, the SWH of total waves obtained from the WAVEWATCH III model output were compared against 
the NDBC buoy data using temporal correlation analyses. The temporal resolution of the NDBC real-time spectra data is $1 \mathrm{~h}$, and to ensure statistical significance, only data of more than 8000 records in 2010 were used. We chose 27 buoys over a time period of 1 February 2010 to 31 December 2010 for our comparison. All the location information for these buoys is input into the model. To save space, only the results from four typical stations are presented here: Station 42003 (in the open ocean), Station 41013 (nearshore), Station 42020 (wind sea dominated for most of the year), and Station 42014 (swell dominated for most of the year). In order to quantify the comparison result, we calculated the correlation coefficient, bias, and root-mean-square (RMS) error between the model output and buoy records. It should be noted that the model's input (wind) is different from the NDBC buoy data. The $10 \mathrm{~m}$ wind speed used to run the model in this paper is the ERA-Interim reanalysis data, whereas the input data for the NDBC buoy is real-time wind data. Jung et al. (2004) [20] compared the analysis products from ERAInterim with various observation-only data products and found that the differences between ERA-Interim and realtime data are generally small. So the difference between these two wind inputs could be ignored. The results are shown in Figure 1, and all the NDBC directional wave stations used in this study are listed in Table 1. We can see that the significant wave height produced by the model shows a strong temporal correlation with real-time data from NDBC observations. The absolute value of significant wave height produced by the model was also shown to correspond well to the NDBC observations.

2.4. Separate Buoy Spectrum Data. In this paper, we extracted the w3partmd.ftn file which directly performs spectral partitioning from the WAVEWATCH III source programs and separates all the buoy two-dimensional spectra. A series of wave parameters were used to calculate the inverse wave age and its corresponding $W_{s}\left(W_{s}=E_{\text {swell }} / E_{\text {total }}\right)$. We intended to establish the relationship between these two parameters with the application of 27 buoys containing direction spectra records in 2010. We eventually investigated more than 20000 records using the high temporal resolution NDBC buoy data. More details are discussed in Section 3.

\section{Results}

3.1. Spatial and Seasonal Distribution of Wind Sea and Swell Energy. The SWH is related to the mean variance of the sea surface elevation $\left(m_{0}\right)$ :

$$
\mathrm{SWH}=H_{s}=4.04 \sqrt{m_{0}}=4.04 \sqrt{\iint f^{0} F(f, \theta) \mathrm{d} f \mathrm{~d} \theta}
$$

where $m_{0}$ is the zeroth moment, $f$ is the frequency, $\theta$ is the propagation direction, and $F(f, \theta)$ is the dimensional spectrum which describes the surface wave energy. Therefore the spatial and seasonal distribution of wave energy can be studied by SWH. The seasonal maps of SWH (total, wind sea, and swell) are shown in Figures 2 and 3. The highest seasonal mean energy of wind sea and swell is found in
TABLE 1: The NDBC directional wave stations used in this study.

\begin{tabular}{|c|c|c|}
\hline Station ID & Latitude and longitude & Depth $(\mathrm{m})$ \\
\hline 41013 & $33.48^{\circ} \mathrm{N} 77.58^{\circ} \mathrm{W}$ & 57 \\
\hline 42001 & $25.86^{\circ} \mathrm{N} 89.67^{\circ} \mathrm{W}$ & 3246 \\
\hline 42002 & $25.17^{\circ} \mathrm{N} 94.42^{\circ} \mathrm{W}$ & 320 \\
\hline 42003 & $25.01^{\circ} \mathrm{N} 85.91^{\circ} \mathrm{W}$ & 3164 \\
\hline 42007 & $30.09^{\circ} \mathrm{N} 88.77^{\circ} \mathrm{W}$ & 13 \\
\hline 42019 & $27.91^{\circ} \mathrm{N} 95.36^{\circ} \mathrm{W}$ & 84 \\
\hline 42020 & $26.95^{\circ} \mathrm{N} 96.70^{\circ} \mathrm{W}$ & 88 \\
\hline 42035 & $29.25^{\circ} \mathrm{N} 94.41^{\circ} \mathrm{W}$ & 16 \\
\hline 42036 & $28.51^{\circ} \mathrm{N} 84.51^{\circ} \mathrm{W}$ & 53 \\
\hline 42039 & $28.80^{\circ} \mathrm{N} 86.06^{\circ} \mathrm{W}$ & 295 \\
\hline 42040 & $29.21^{\circ} \mathrm{N} 88.20^{\circ} \mathrm{W}$ & 238 \\
\hline 44014 & $36.61^{\circ} \mathrm{N} 74.84^{\circ} \mathrm{W}$ & 48 \\
\hline 44025 & $40.25^{\circ} \mathrm{N} 73.17^{\circ} \mathrm{W}$ & 40 \\
\hline 45001 & $48.07^{\circ} \mathrm{N} 87.78^{\circ} \mathrm{W}$ & 165 \\
\hline 45003 & $45.35^{\circ} \mathrm{N} 82.84^{\circ} \mathrm{W}$ & 137 \\
\hline 45005 & $41.68^{\circ} \mathrm{N} 82.40^{\circ} \mathrm{W}$ & 15 \\
\hline 45007 & $42.68^{\circ} \mathrm{N} 87.03^{\circ} \mathrm{W}$ & 165 \\
\hline 45012 & $43.62^{\circ} \mathrm{N} 77.41^{\circ} \mathrm{W}$ & 145 \\
\hline 46028 & $35.74^{\circ} \mathrm{N} 21.89^{\circ} \mathrm{W}$ & 1112 \\
\hline 46029 & $46.12^{\circ} \mathrm{N} 24.51^{\circ} \mathrm{W}$ & 140 \\
\hline 46041 & $47.34^{\circ} \mathrm{N} 124.75^{\circ} \mathrm{W}$ & 130 \\
\hline 46042 & $36.75^{\circ} \mathrm{N} 122.42^{\circ} \mathrm{W}$ & 1920 \\
\hline 46069 & $33.65^{\circ} \mathrm{N} 120.20^{\circ} \mathrm{W}$ & 1005 \\
\hline 46086 & $32.50^{\circ} \mathrm{N} 118.00^{\circ} \mathrm{W}$ & 1857 \\
\hline 46087 & $48.49^{\circ} \mathrm{N} 124.73^{\circ} \mathrm{W}$ & 37 \\
\hline 46088 & $48.33^{\circ} \mathrm{N} 123.17^{\circ} \mathrm{W}$ & 106 \\
\hline 51028 & $0.02^{\circ} \mathrm{S} 153.87^{\circ} \mathrm{W}$ & 4572 \\
\hline
\end{tabular}

the extratropical areas. In the northern hemisphere, wave energy is concentrated in the northern Pacific and northern Atlantic Oceans. In the southern hemisphere, wave energy is continuously distributed along the south westerlies. In DJF (December, January, and February), the values of both wind sea and swell energy in the northern hemisphere are higher than in the southern hemisphere. By contrast in JJA (June, July, and August), the values of both wind sea and swell energy in the southern hemisphere are higher. This is dependent on the seasonal change of wind speed in the westerly sea storm areas. Because, on the one hand, wind sea is strongly aligned with the wind, strong westerly winds produce strong wind sea waves. On the other hand, although swell exists almost everywhere in the global ocean, the westerly sea storm areas in respective hemispheres are the main source areas of swell [21]. Seasonal mean wind speed in the north westerlies reaches a maximum in DJF and then gradually decreases in MAM (March, April, and May) and reaches a minimum in JJA, while, in the southern westerlies, the maximum appears in JJA and the minimum appears in DJF. So the highest seasonal mean energy of swell and wind sea is distributed in the respective winter hemispheres. The total wave energy in the Arabian Sea is different from the northern hemisphere overall trend being higher in summer 

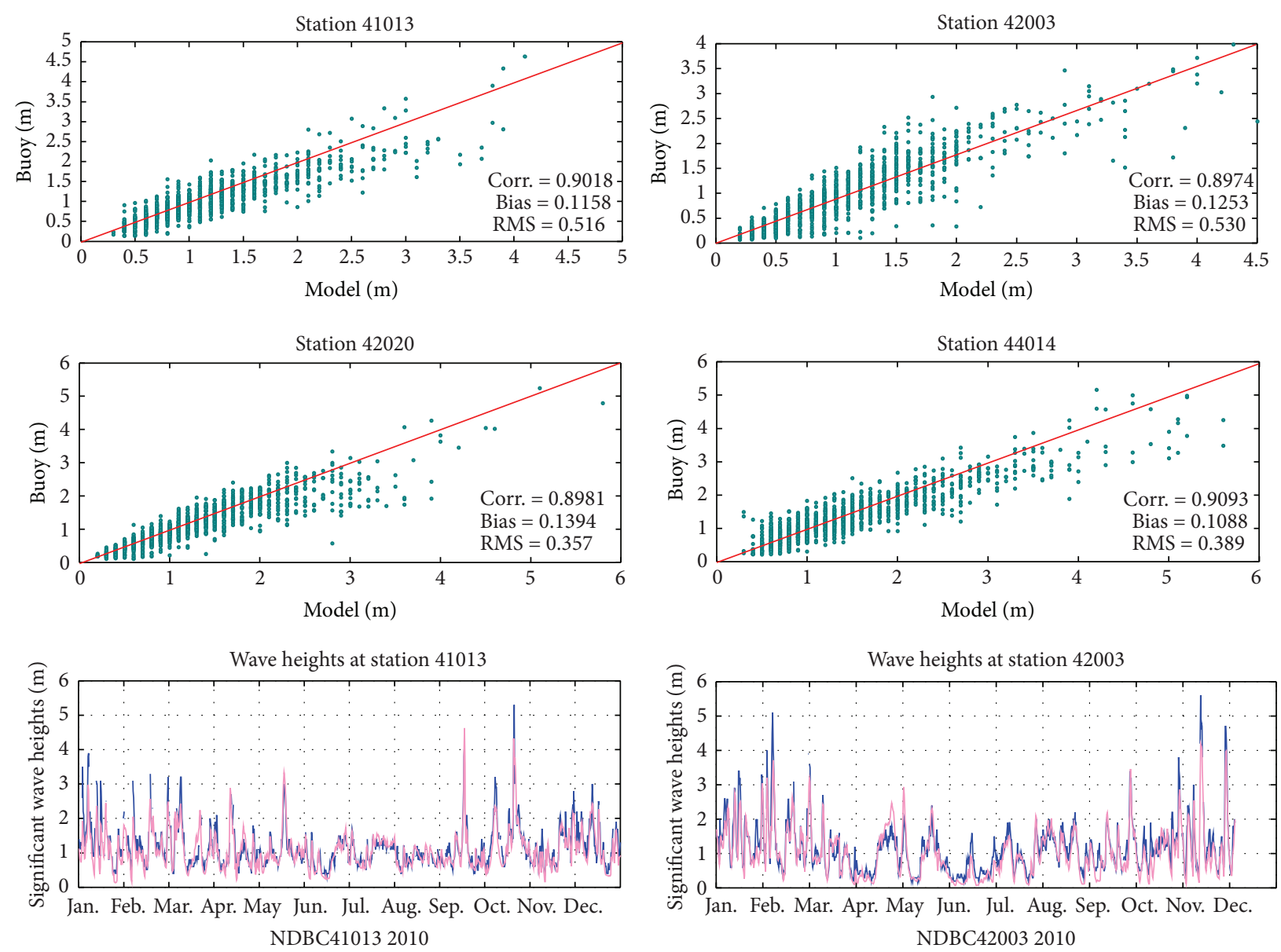

NDBC42003 2010
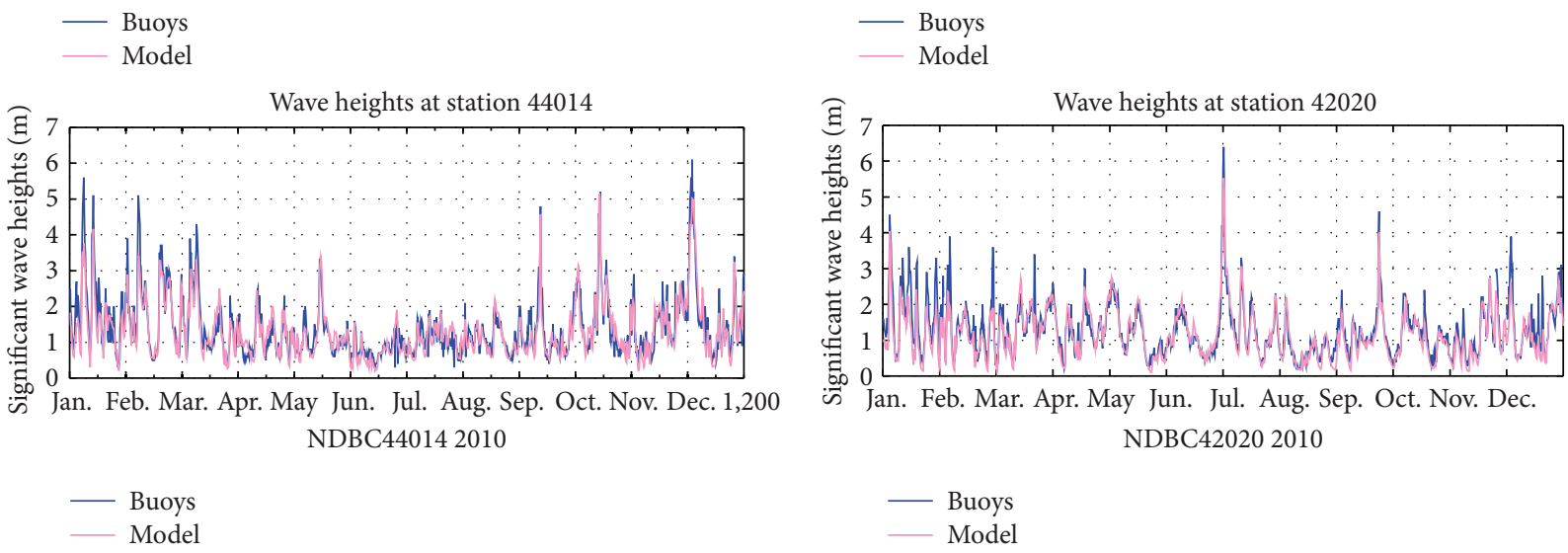

FIGURE 1: The comparison results between model output and buoy records.

than in winter. That is because strong summer monsoons produce a lot of energy to generate wind sea waves, while winter monsoons are much weaker. The maximum for both wind sea and swell energy over the whole year is found in the southern Indian Ocean areas because they are influenced by the southwesterly winds.

Table 2 shows the regional distribution of wind sea energy. When the three main oceans are compared, the Pacific Ocean accounts for the largest proportion of the whole year's total wind sea energy $(53.27 \%)$, followed by the Atlantic Ocean (30.57\%) and the Indian Ocean (16.15\%). Table 3 shows the regional distribution of swell energy. The Pacific Ocean accounts for the largest proportion (67.74\%), followed by the Atlantic Ocean (28.9\%) and the Indian Ocean (13.37\%). These two proportions for wind sea energy and swell energy are similar and relate to ocean area. The area of the global ocean is $3.61 \times 10^{8} \mathrm{~km}^{2}$, with the Pacific accounting for $42.8 \%$, the Atlantic Ocean for $24.1 \%$, and the Indian Ocean for $19.6 \%$. Compared with swell energy, the regional distribution of wind sea energy is highly affected by the 
TABLE 2: The regional distribution of wind sea energy.

\begin{tabular}{lccccc}
\hline Regions & MAM & JJA & SON & DJF & Total \\
\hline Northern Pacific Ocean & $15.36 \%$ & $5.67 \%$ & $10.96 \%$ & $23.69 \%$ & $31.19 \%$ \\
Southern Pacific Ocean & $40.91 \%$ & $43.18 \%$ & $43.62 \%$ & $70.08 \%$ \\
Northern Atlantic Ocean & $7.44 \%$ & $3.26 \%$ & $7.77 \%$ & $16.74 \%$ & $8.27 \%$ \\
Southern Atlantic Ocean & $22.45 \%$ & $24.76 \%$ & $22.28 \%$ & $18.77 \%$ & $9.34 \%$ \\
Indian Ocean & $14.55 \%$ & $23.14 \%$ & $15.37 \%$ & $16.15 \%$ \\
\hline
\end{tabular}

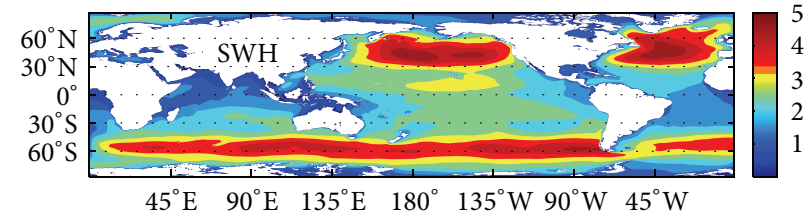

(a)

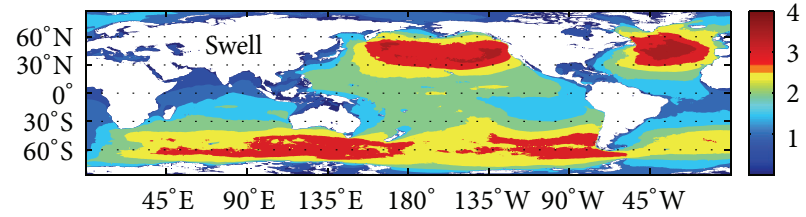

(b)

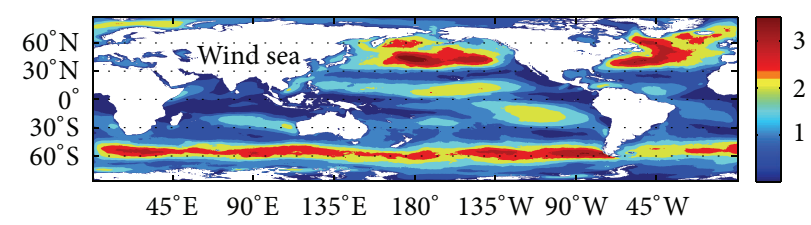

(c)

Figure 2: Seasonal averages for DJF of (a) SWH (m), (b) wave height of swell (m), and (c) wave height of wind sea (m).

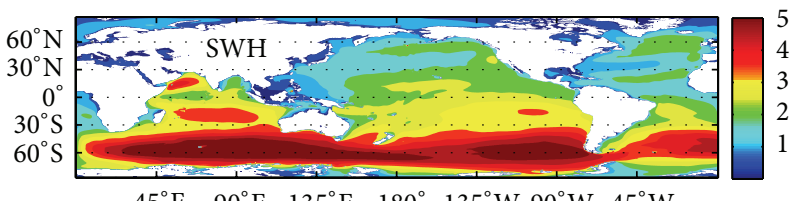

$45^{\circ} \mathrm{E} \quad 90^{\circ} \mathrm{E} \quad 135^{\circ} \mathrm{E} \quad 180^{\circ} 135^{\circ} \mathrm{W} 90^{\circ} \mathrm{W} \quad 45^{\circ} \mathrm{W}$

(a)

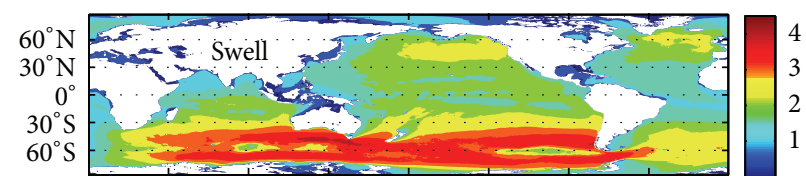

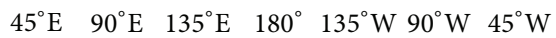

(b)

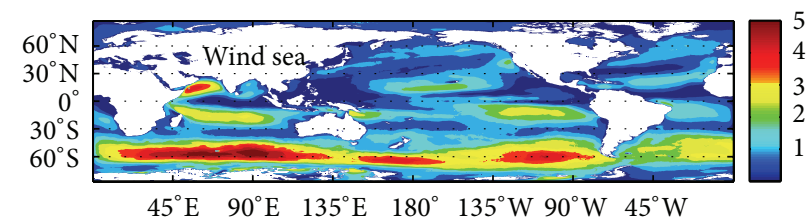

(c)

FIGURE 3: Seasonal averages for JJA of (a) SWH (m), (b) wave height of swell (m), and (c) wave height of wind sea (m).

seasons. In JJA, wind sea energy in the northern Pacific Ocean only accounts for $5.67 \%$ of all global wind sea energy, while, in DJF, it increases to $26.69 \%$. Dramatic seasonal change also occurs in the northern Atlantic and the Indian Ocean. The Indian summer monsoon is much stronger than the winter monsoon, which means that wind sea energy accounts for $23.14 \%$ of all the global wind sea energy in JJA but this percentage reduces to $9.34 \%$ in DJF. Clearly, the regional distribution of swell energy shows much stronger seasonal stability than that of wind sea energy.

3.2. Energy Content of the Wind Sea and Swell Fields. The DJF and JJA global distribution of the proportion of swell energy to total wave energy ( $\left.W_{s}=E_{\text {swell }} / E_{\text {total }}\right)$ is shown in Figure 4. Swell carries a large part of the wave energy with $W_{s}$ being higher than $50 \%$ in most seas. The value of $W_{s}$ shows obvious zonal banded distribution. High $W_{s}$ values (over 90\%) show low seasonality and occur in the calm belt near the equator and subtropical high pressure belts near $30^{\circ} \mathrm{N}$ and $30^{\circ} \mathrm{S}$. However the spatial distribution of low $W_{s}(50 \% \sim 60 \%)$ is highly affected by the seasons. In DJF, it is in the northern westerlies controlled areas and, in JJA, it is along with the southern westerly belt. $W_{s}$ is lower along the eastern continental coasts $(<50 \%)$ but increases to $90 \%$ in most of the western coasts which relate to wave transport and reflects swell energy reinforcement on the western continental coasts.

3.3. Swell Probability. Chen et al. (2002) [12] used the windwave relation for fully developed seas [22] to classify swells 
TABLE 3: The regional distribution of swell energy.

\begin{tabular}{|c|c|c|c|c|c|}
\hline Regions & MAM & JJA & SON & DJF & Total \\
\hline Northern Pacific Ocean & $14.74 \%$ & $15.20 \%$ & $13.99 \%$ & $17.60 \%$ & $14.86 \%$ \\
\hline Southern Pacific Ocean & $44.14 \%$ & $40.14 \%$ & $43.96 \%$ & $37.21 \%$ & $42.88 \%$ \\
\hline Northern Atlantic Ocean & $6.65 \%$ & $6.18 \%$ & $7.48 \%$ & $18.47 \%$ & $7.74 \%$ \\
\hline Southern Atlantic Ocean & $21.00 \%$ & $24.31 \%$ & $20.82 \%$ & $16.99 \%$ & $21.16 \%$ \\
\hline Indian Ocean & $13.45 \%$ & $13.16 \%$ & $13.75 \%$ & $9.73 \%$ & $13.37 \%$ \\
\hline
\end{tabular}

TABLE 4: Seasonal variations of the swell probability $\left(P_{s}\right)$.

\begin{tabular}{|c|c|c|c|c|c|}
\hline Regions & MAM & JJA & SON & DJF & Total \\
\hline Northern Pacific Ocean & $84.15 \%$ & $90.84 \%$ & $85.84 \%$ & $79.16 \%$ & $85.04 \%$ \\
\hline Southern Pacific Ocean & $93.50 \%$ & $87.79 \%$ & $86.59 \%$ & $88.61 \%$ & $84.01 \%$ \\
\hline Northern Atlantic Ocean & $87.07 \%$ & $90.23 \%$ & $83.41 \%$ & $80.01 \%$ & $88.73 \%$ \\
\hline Southern Atlantic Ocean & $86.65 \%$ & $82.43 \%$ & $80.00 \%$ & $83.99 \%$ & $88.19 \%$ \\
\hline Indian Ocean & $94.99 \%$ & $85.36 \%$ & $87.05 \%$ & $91.66 \%$ & $92.95 \%$ \\
\hline Global & $84.23 \%$ & $84.57 \%$ & $88.93 \%$ & $86.91 \%$ & $87.85 \%$ \\
\hline
\end{tabular}

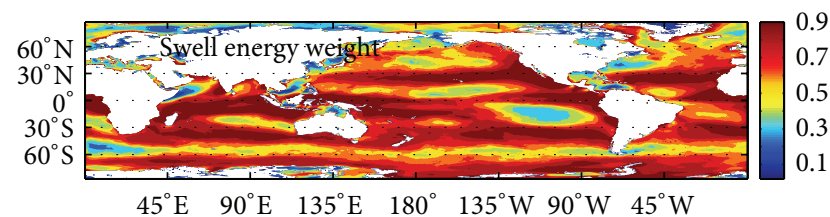

(a)

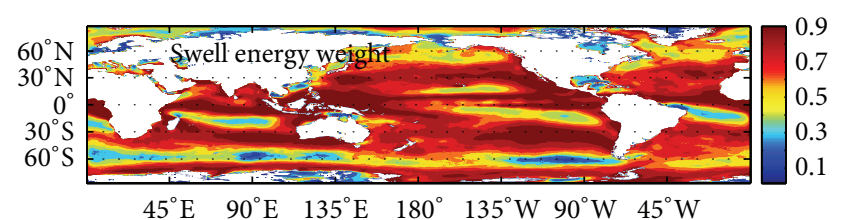

(b)

FIGURE 4: Global distributions of the swell energy proportion to the total wave energy $\left(W_{s}\right)$ for (a) DJF and (b) JJA.

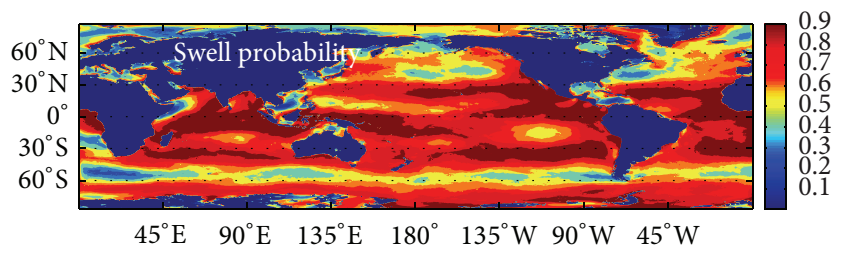

(a)

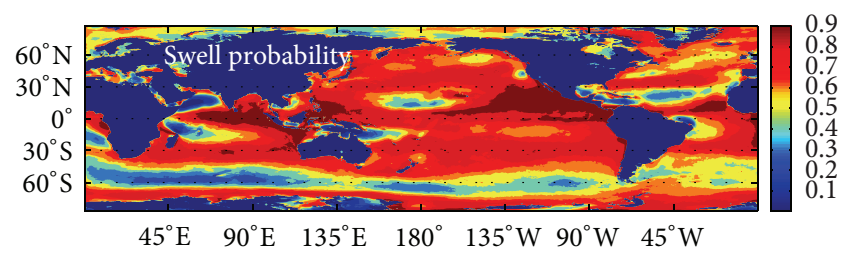

(b)

FIGURE 5: Global distributions of the swell probability $\left(P_{s}\right)$ for (a) DJF and (b) JJA.

from wind waves. At a given location, they defined the sea state as swell if the SWH was greater than the value predicted by the wind-wave relation, while the sea state was considered as a growing sea in cases where the SWH was less than the predicted value. They also introduced a probability index, $P_{s}$, to quantify the frequencies of swell occurrences. In fact, the "swells" and "growing sea" mentioned by Chen et al. (2002) are a sea state of mixed seas (composed of wind sea and swell) and a sea state of pure wind sea. In this paper, we calculate the swell probability by redefining the sea state as swell if $W_{s}$ is greater than $0 \%$ and the sea state as a growing sea if $W_{s}$ is $0 \%$. Results are shown in Figure 5 and the detailed values are shown in Table 4.

Compared with the results calculated by Chen et al. (2002) [12], $P_{s}$ in this paper is more concrete. Obviously, swell exists almost everywhere and every moment in the global wave fields. In particular, at low latitudes, swells exist all the time with $P_{s}$ higher than 95\%. Chen et al. (2002) [12] defined these areas with extremely high $P_{s}$ values as "swell pools." In fact, the location of the swell pools changes with the season. In JJA, there were two swell pools located in the tropical and subtropical areas in the northern Indian Ocean and eastern Pacific Ocean, while, in DJF, the swell pool in the Indian Ocean expanded and filled most of the northern Indian Ocean. There were also some tongue-shaped swell pools located in the low latitude areas in the eastern Pacific and Atlantic Ocean. The global $P_{s}$ shows little seasonality and always remains at around $85 \%$. When the three main oceans are compared, the Indian Ocean has the highest swell probability (92.95\%), followed by the Atlantic Ocean $(88.60 \%)$ and the Pacific Ocean (84.54\%). 


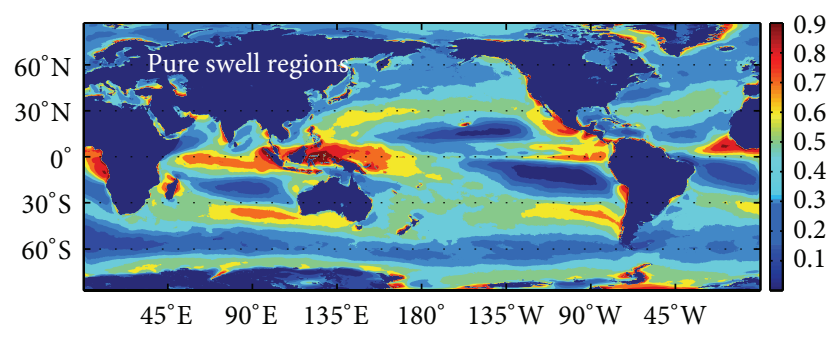

FIGURE 6: The distribution and frequency of occurrences of pure swell areas.

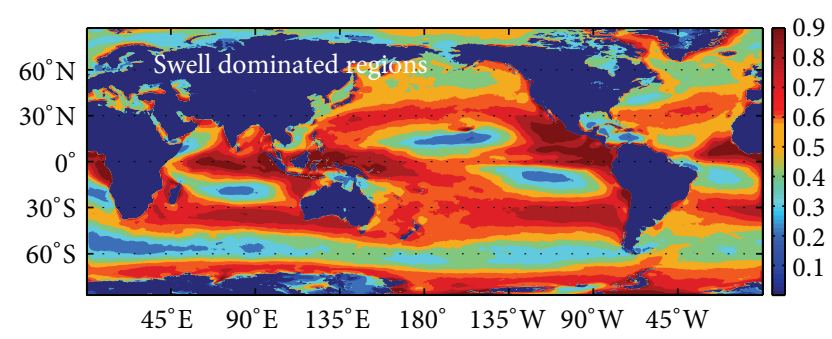

FIGURE 7: The distribution and frequency of occurrences of swell dominated areas (for 2010 whole year).

\subsection{Frequency of Occurrences of High Swell (Wind Sea) Energy} Areas. There are some distinctive areas in the global wave fields which are dominated by either high or low values of swell or wind sea energy. In this paper, we try to find these distinctive areas and analyze their frequency of occurrence. Firstly, we define four types of distinctive areas as pure wind sea area, wind sea dominated area, swell dominated area, and pure swell area. Since we have calculated $W_{s}$ of each grid, we use a similar statistical method proposed by Hanley et al. (2010) [23] to calculate the results. A variable is defined as 1 if $W_{s}$ is $0 \%$ (pure wind sea area) and 0 otherwise. Taking an average of the fraction of time $(365 * 4)$ we get the frequency of occurrence of the pure wind sea area in the world ocean. The same method is used to find the other three types of distinctive areas, but $W_{s}$ of them are all different. $W_{s}$ of pure swell area is $100 \%$, the swell dominated area is from $50 \%$ to $100 \%$, and the wind sea dominated area is from $0 \%$ to $50 \%$.

We found that pure wind sea grids were scattered implying that pure wind sea regions are very rare in the world's ocean wave fields. Some small pure wind sea areas may exist in closed or semiclosed seas but they were not found in our study. As shown in Figure 6, two pure swell regions with frequency of occurrence over $90 \%$ were found in nearby regions of Indonesia and nearby regions of Cape Verde in the east of the African continent. The annual mean significant wave height of these areas was about 1 to 1.5 meters with little wave energy. Figure 7 shows that there are four swell dominated areas with frequency of occurrence close to $100 \%$. These are in the coast waters off Indonesia, in the northern Indian Ocean, in the equatorial waters in the west of central America and Africa, and a tongue-shaped region near the western boundary of central South America. Three of these swell dominated areas are in the same location with "swell pools" identified by Chen et al. (2002) [12]. Regions

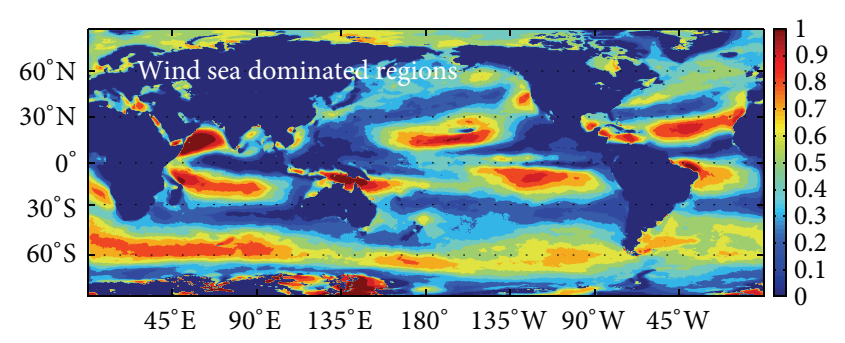

FIGURE 8: The distribution and frequency of occurrences of wind sea dominated areas (for June, July, and August).

which occur in the western coast of each continent also have a very high frequency of over $85.7 \%$ swell domination. Swell dominated areas with high frequency are far away from the swell generation regions (the westerly sea storm areas in the south Pacific, south Atlantic, and the southern Indian Ocean) but are close to the regions with low wind speed. The distribution of wind sea dominated areas showed strong seasonality and only occur in June, July, and August, so only these three months are shown in Figure 8. Wind sea dominated areas occur most frequently (over 90\%) in the southern westerlies controlled regions. Three wind sea dominated areas occur frequently (over $80 \%$ ) in a region near the east of Australia (affected by the southeast trade winds in the northern hemisphere), the Arabian sea (affected by the Indian summer monsoon), and mid-latitude regions in northern Pacific and northern Atlantic Ocean (affected by the southwest trade winds in the northern hemisphere). This is in agreement with Chen et al. (2002) [12] who found that wind seas are most common in the mid-latitude storm tracks.

3.5. The Link between Inverse Wave Age and $W_{s}$. The wave age concept, originally defined by Pierson and Moskowitz (1964) [13], is the traditional parameter to classify swells from wind sea waves. Hasselmann (1988) [22] used inverse wave age as an identifier to show the predominance of swell or wind sea: the wind sea components dominate when the value of the inverse wave age is larger than 0.83 , and the swell prevails when the value of the inverse wave age is less than 0.15 . It seems that the value of the inverse wave age in part reflects the presence of swell and wind sea. Now using the SEP method, we can separate the two-dimensional spectrum of any sea state and get all of its wave parameters. The inverse wave age and $W_{s}$ can be calculated and the links between these two criteria can be established. In this paper the inverse wave age $\beta$ is defined as

$$
\beta=\frac{U \cos \theta}{C p}=\frac{U \cos \theta 2 \pi}{g T p},
$$

where $C p$ and $T p$ are the phase velocity and period of total waves, $U$ is $10 \mathrm{~m}$ wind speed, and $\theta$ is the relative angle between the wind and the waves. All of the wave parameters are calculated using the SEP method introduced in Section 2. Results are shown in Figure 9. We can draw a conclusion that the overall trend is that $W_{s}$ decreases with an improvement of the inverse wave age. The wind sea energy will occur only 


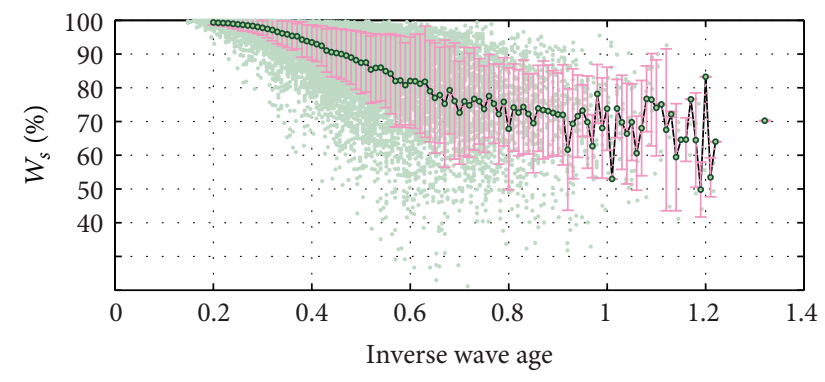

FIGURE 9: Relationship between inverse wave age and $W_{s}$.

if the value of the inverse wave age exceeds 0.18 . We tried to draw a fitting curve between these two parameters but as the $W_{s}$ values of most points were greater than 0.5 , the curve became fluctuating when the value of the inverse wave age exceeded 0.8 . The $W_{s}$ value covering from 0 to 0.5 should be the subject of future research.

\section{Conclusions}

In this paper, we used the ECMWF Era-Interim wind data to run the WAVEWATCH III model and reproduced the global wave fields in 2010. After separating wind sea and swell from mixed waves, we studied the spatial and seasonal distribution of swell and wind sea energy. We found that the highest seasonal mean energy of swell and wind sea is distributed in the respective winter hemispheres, along the westerly storm areas. We calculated two commonly used indicators, $W_{s}$ (the swell energy proportion to the total wave energy) and $S_{p}$ (swell probability), of the global wave fields and found that swell energy accounts for a larger proportion of the total wave energy in most areas. The value of $W_{s}$ shows obvious zonal banded distribution. High $W_{s}$ values occur along the calm belt near the equator and subtropical high pressure belt near $30^{\circ} \mathrm{N}$ and $30^{\circ} \mathrm{S}$. The $W_{s}$ value is much lower along the eastern continental coasts than the western coasts which reflects the swell reinforcement on the western continental coasts. We also found some distinctive areas which are dominated by high values of swell or wind sea and calculated their frequency of occurrence. Data from 27 NDBC buoys were used to examine the model output. Based on the SEP method, we separated buoy directional spectra and obtained detailed spectral parameters to calculate the inverse wave age and $W_{s}$. We found that the value of inverse wave age improves when $W_{s}$ declines and wind sea energy appears only if the value of the inverse wave age exceeds 0.18 .

Despite the use of different wind datasets and different sea-swell separation criteria, there is a good agreement with previous studies. Using a wave model is the most effective way to get a sufficiently long spectral description of the wave field. This study is a meaningful attempt to isolate wind sea and swell characteristics by spectral partitioning. In further research, a longer time series of the global wave fields should be reproduced which will more reliably reflect the seasonal change of swell or wind sea energy distribution. In addition, SWAN is better than WAVEWATCH in shallow water wave field simulation [24], so nested operation of these two models should be applied in further studies.

\section{Conflict of Interests}

The authors declare that there is no conflict of interests regarding the publication of this paper.

\section{Acknowledgments}

This study is supported by the National Natural Science Foundation of China (no. 41376010) and Zhejiang Provincial Natural Science Foundation of China under Grant no. LQ14D060001. The supports from the National Natural Science Foundation of China are appreciated (Grant nos. 41276010 and U1406401).

\section{References}

[1] W. Wang and R. X. Huang, "Wind energy input to the surface waves," Journal of Physical Oceanography, vol. 34, no. 5, pp. 1276-1280, 2004.

[2] R. X. Huang and W. Wang, "Decadal variability of wind energy input to the world ocean," Deep-Sea Research II, vol. 34, pp. 3141, 2006.

[3] A. A. Grachev and C. W. Fairall, "Upward momentum transfer in the marine boundary layer," Journal of Physical Oceanography, vol. 31, no. 7, pp. 1698-1711, 2001.

[4] P. A. E. M. Janssen, "Wave-induced stress and the drag of air flow over sea waves," Journal of Physical Oceanography, vol. 19, no. 6, pp. 745-754, 1989.

[5] M. A. Donelan, W. M. Drennan, and K. B. Katsaros, "The air-sea momentum flux in conditions of wind sea and swell," Journal of Physical Oceanography, vol. 27, no. 10, pp. 2087-2099, 1997.

[6] C. Guan and L. Guan, "On the linear parameterization of drag coefficient over sea surface," Journal of Physical Oceanography, vol. 34, no. 12, pp. 2847-2851, 2004.

[7] S. F. Barstow, World Wave Atlas, AVISO Newsletter no. 4, AVISO, Ramonville-Saint-Agne, France, 1996.

[8] I. R. Young, "Seasonal variability of the global ocean wind and wave climate," International Journal of Climatology, vol. 19, no. 9, pp. 931-950, 1999.

[9] A. Semedo, K. Sušelj, A. Rutgersson, and A. Sterl, "A global view on the wind sea and swell climate and variability from ERA-40," Journal of Climate, vol. 24, no. 5, pp. 1461-1479, 2011.

[10] S. K. Gulev and L. Hasse, "North Atlantic wind waves and wind stress fields from voluntary observing ship data," Journal of Physical Oceanography, vol. 28, no. 6, pp. 1107-1130, 1998.

[11] J. F. Liu, W. Jiang, M. G. Yu et al., "An analysis on annual variation of monthly mean sea wave fields in North Pacific Ocean," Journal of Tropical Oceanography, vol. 21, no. 3, pp. 36469, 2002 (Chinese).

[12] G. Chen, B. Chapron, R. Ezraty, and D. Vandemark, "A global view of swell and wind sea climate in the ocean by satellite altimeter and scatterometer," Journal of Atmospheric and Oceanic Technology, vol. 19, no. 11, pp. 1849-1859, 2002.

[13] W. J. Pierson and L. Moskowitz, "A proposed spectral form for fully developed wind seas based on the similarity theory of S. A. Kitaigorodskii," Journal of Geophysical Research, vol. 69, no. 24, pp. 5181-5190, 1964. 
[14] J. Zhang, W. Wang, and C. Guan, "Analysis of the global swell distributions using ECMWF Re-analyses wind wave data," Journal of Ocean University of China, vol. 10, no. 4, pp. 325-330, 2011.

[15] T. W. Gerling, "Partitioning sequences and arrays of directional wave spectra into component wave systems," Journal of Atmospheric and Oceanic Technology, vol. 9, no. 4, pp. 444-458, 1992.

[16] J. L. Hanson and O. M. Phillips, "Automated analysis of ocean surface directional wave spectra," Journal of Atmospheric and Oceanic Technology, vol. 18, no. 2, pp. 277-293, 2001.

[17] J. L. Hanson and R. E. Jensen, "Wave system diagnostics for numerical wave models," in Proceedings of the 8th International Workshop on Wave Hindcasting and Forecasting, Technical Report no. 29, WMO/TD-no. 1319, Joint WMO/IOC Technical Commission for Oceanography and Marine Meteorology, Oahu, Hawaii, USA, November 2004.

[18] J. L. Hanson, B. Tracy, H. Tolman, and D. Scott, "Pacific hindcast performance evaluation of three numerical wave models," in Proceedings of the 9th International Workshop on Wave Hindcasting and Forecasting, Victoria, Canada, September 2006.

[19] L. Vincent and P. Soille, "Watersheds in digital spaces: an efficient algorithm based on immersion simulations," IEEE Transactions on Pattern Analysis and Machine Intelligence, vol. 13, no. 6, pp. 583-598, 1991.

[20] T. Jung, E. Klinker, and S. M. Uppala, "Reanalysis and reforecast of three major European storms of the twentieth century using the ECMWF forecasting system. Part I. Analyses and deterministic forecasts," Meteorological Applications, vol. 11, no. 4, pp. 343-361, 2004.

[21] J.-H. G. M. Alves, "Numerical modeling of ocean swell contributions to the global wind-wave climate," Ocean Modelling, vol. 11, no. 1-2, pp. 98-122, 2006.

[22] S. Hasselmann, "The WAM model-a third generation ocean wave prediction model," ournal of Physical Oceanography, vol. 18, no. 12 , pp. 1775-1810, 1988.

[23] K. E. Hanley, S. E. Belcher, and P. P. Sullivan, "A global climatology of wind-wave interaction," Journal of Physical Oceanography, vol. 40, no. 6, pp. 1263-1282, 2010.

[24] N. Booij, R. C. Ris, and L. H. Holthuijsen, "A third-generation wave model for coastal regions: 1 . Model description and validation," Journal of Geophysical Research C: Oceans, vol. 104, no. 4, pp. 7649-7666, 1999. 

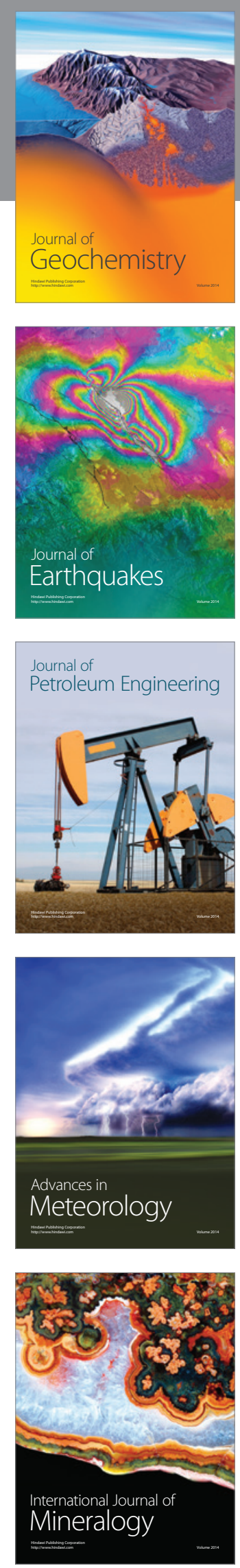
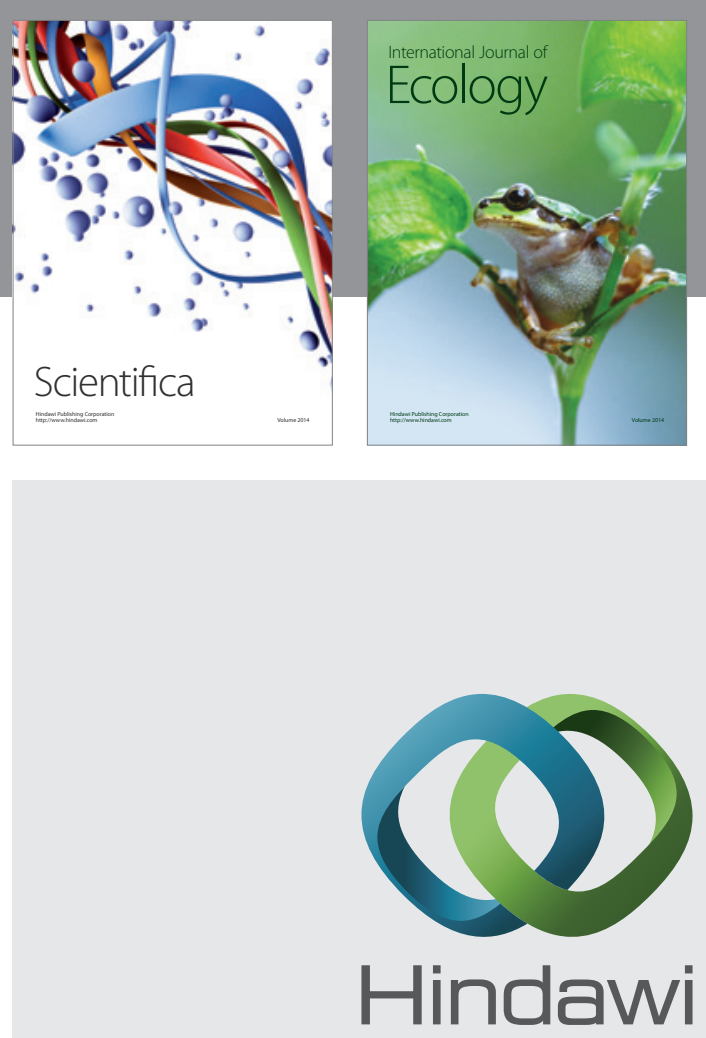

Submit your manuscripts at

http://www.hindawi.com
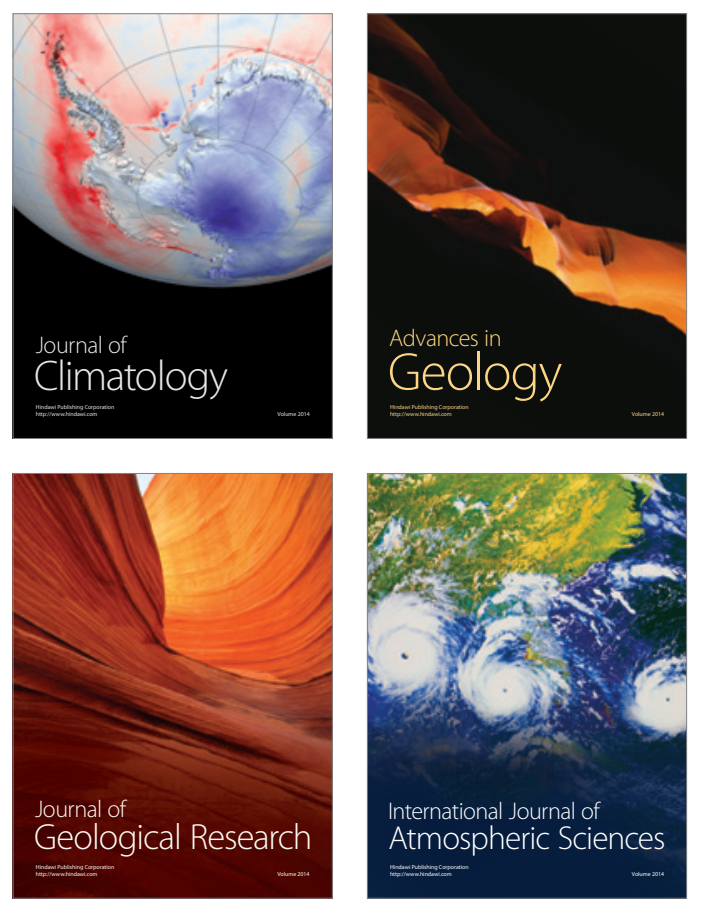

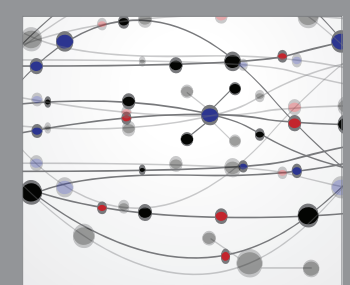

The Scientific

\section{World Journal}
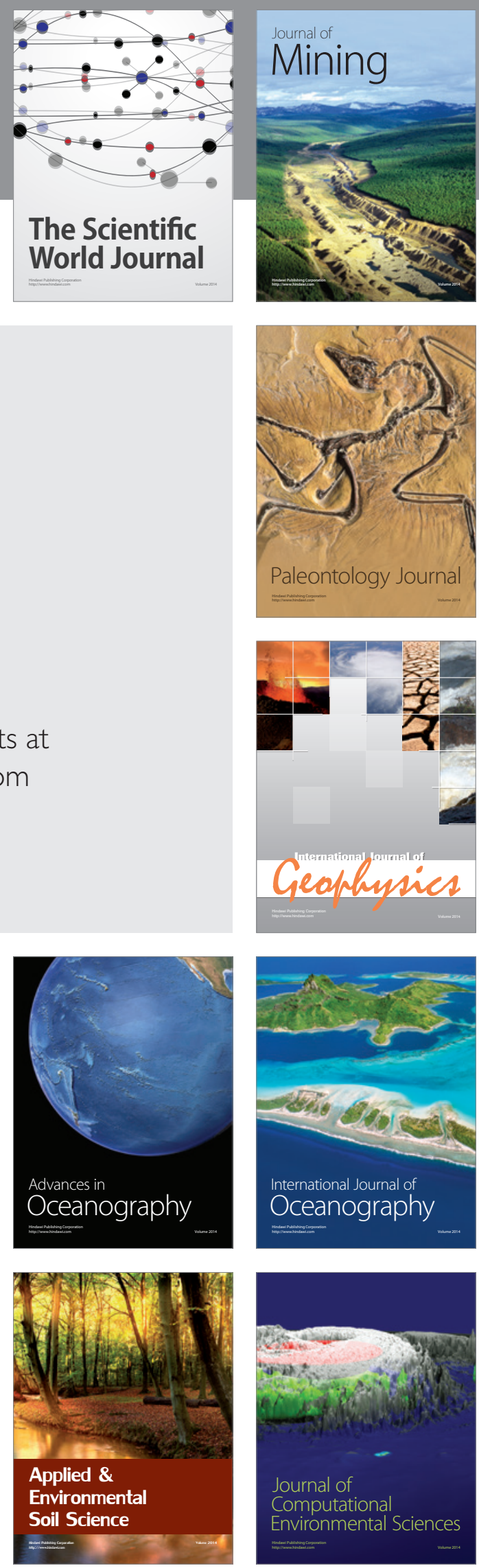